\title{
Using the needs of WHO to prioritise Cochrane reviews: The case of antipsychotic drugs
}

Marianna Purgato ${ }^{1,2^{*}}$, Corrado Barbui ${ }^{1}$ and Clive E Adams ${ }^{2}$

\begin{abstract}
Background: This study aimed to investigate existing trialling activity relating to three antipsychotic drugs from the WHO List of Essential Medicines (chlorpromazine, fluphenazine decanoate, haloperidol), link existing trials to existing Cochrane reviews, identify gaps in reviewing activity on accessible treatments for people with schizophrenia.

Methods: We used the Cochrane Schizophrenia Group's register searching for all studies comparing the three antipsychotic drugs with each other and with all other pharmacological interventions listed on the Essential Medicines List (with the addition of 'placebo or no drug'). For each we also considered studies that focussed on administration, dose, withdrawal and use of that drug in specific circumstances administration. Data were then extracted on a number of studies, number of participants within those studies, and as to whether a maintained review already exists. Finally, every effort was made to consider as to whether there were possibilities for missing comparisons that no one had ever investigated.

Results: There has been considerable research activity involving the three 'essential' antipsychotics and also comparing those three drugs to others on the 'essential' list. We found 490 studies with 77957 participants for haloperidol, 316 studies with 29179 participants for chlorpromazine and 33 studies with 4503 participants for fluphenazine decanoate. Reviewing activity has also been considerable in this area but there are notable omissions which would necessitate new reviews to comprehensively cover the area.

Conclusions: We have used the 'sample frame' of the WHO Essential drug list as a starting point. WHO prioritises for us those drugs that have universal accessibility but they may not be the compounds that are first choice if others are available. It is encouraging to see how many maintained reviews already exist to service those undertaking $\mathrm{WHO}$ guidelines. The needs of those guiding care can be taken as a means of prioritising research. For largest global impact WHO Essential Medicine list provides clear direction. By using this technique workload can be anticipated, prioritising can take place for new reviews and updates.
\end{abstract}

\section{Background}

The Cochrane Collaboration is a unique organisation producing as well as maintaining systematic reviews, mostly focussed on the effects of healthcare interventions [1]. These reviews are regularly maintained in the light of new evidence or valid criticism. The Cochrane Library has been shown to contain the highest grade reviews of any publication [2].

With the enormous task of summarising the effects of all healthcare interventions (and maintaining those

\footnotetext{
*Correspondence: marianna.purgato@univr.it

'Department of Public Health and Community Medicine, Section of

Psychiatry and Clinical Psychology, University of Verona, Verona, Italy

Full list of author information is available at the end of the article
}

summaries) it is a logistical, ethical and moral dilemma where to focus efforts. Prioritising in the midst of so much of a 'confusion of evidence' has, for some time, troubled the Collaboration as a whole [3].

Mental health is no exception. The randomised controlled trial is the most powerful means of evaluating mental health treatments [4]. The five mental health Cochrane groups currently produce and maintain 512 reviews on the Cochrane Library but these remain a small fraction of the potential numbers of relevance and interest. With limited resources it is imperative that energies are not dissipated in producing reviews that are likely to be of little value to people with mental health problems. A series of competing priorities often results

\section{Biomed Central}


in continuation of the status quo - where the priorities of reviewer, or the editorial base, take precedence over others.

The recently produced WHO guidance on the care of people with mental health problems offered an opportunity to explore a technique for prioritisation [5]. 80\% of the world's population with schizophrenia live in low and middle income countries. The mainstay of treatment of people with serious mental illnesses such as schizophrenia remains antipsychotic drugs but many of these drugs are unavailable worldwide or are available only to the rich.

WHO, have drawn up a list of drugs they designate as 'essential' [6]. "Essential medicines are those that satisfy the priority health care needs of the population. They are selected with due regard to public health relevance, evidence on efficacy and safety, and comparative costeffectiveness. Essential medicines are intended to be available within the context of functioning health systems at all times in adequate amounts, in the appropriate dosage forms, with assured quality and adequate information, and at a price the individual and the community can afford."[6] This list includes over 350 medicines of which twelve are for mental and behavioural disorders: amitriptyline and fluoxetine for depressive disorder; carbamazepine, lithium carbonate and valproic acid for bipolar disorder, diazepam for anxiety disorder; clomipramine for obsessive-compulsive disorder; nicotine replacement therapy and methadone for disorders due to psychoactive substance use. The list includes only three drugs for psychotic disorder: chlorpromazine, haloperidol, and fluphenazine decanoate.

In these years several applications have been submitted to WHO to include other drugs in the Essential List of Medicine. The list of rejected drugs includes 51 pharmacological interventions of which 12 are psychotropic drugs (6 antipsychotics, 4 antidepressants, 1 anticonvulsant, 1 benzodiazepine) [7]. The reasons for rejection are not clear. Regarding antipsychotics, for example, Clozapine is mentioned in the WHO Intervention guide [5] for "treatment resistant schizophrenia" (those who have not responded to other antipsychotic agents at adequate dosages for adequate duration) but, nevertheless, appears in the rejected drugs list. Rejection could be from a series of factors such as evidence, cost, distribution, or/and ease of use.

In 2010, those drawing up the guidance for WHO contracted the Cochrane Schizophrenia Group to produce summaries of the findings of reviews relevant to these drugs, using the Grading of Recommendations, Assessment, Development and Evaluation (GRADE) approach [8]. This methodology is suitable for summarizing the evidence extracted from systematic reviews and meta-analyses into "Summary of Findings (SoF) tables"; grading the quality of evidence summarized in SoF tables; and grading the strength of treatment recommendations [9].

This resulted in approximately forty summaries of findings from existing best evidence in Cochrane reviews. It also highlighted the possibility that some useful data may not have been systematically reviewed and therefore were not available to policy makers with global impact.

\section{Aims}

To use WHO 'essential' antipsychotic drugs as a sampling frame, investigate existing trialling activity relating to each of these antipsychotic drugs, link existing trials to existing Cochrane reviews. We aim at identifying gaps in reviewing activity on accessible treatments for people with schizophrenia, in order to prioritise Cochrane reviews using the needs of WHO.

\section{Methods}

We used the Cochrane Schizophrenia Group's register that contains 16,000 citations to approximately 13,000 studies. This register is complied of regular searching of 71 databases and is considerably more comprehensive that can be found either on Medline, PsycInfo, EMBase, or even the Cochrane Central Register of Trials [10]. This represents the most comprehensive register of subject-specific trials in existence. These studies are reliably indexed [11] regarding the intervention and the number of participants.

MP systematically searched the register for all studies comparing the three antipsychotic drugs with each other and with all other pharmacological interventions listed on the Essential Medicines List (with the addition of the intervention of 'placebo or no drug'). For each we also considered studies that focussed on administration, dose, withdrawal and use of that drug in specific circumstances administration.

Data were then extracted on a number of studies, number of participants within those studies, and as to whether a maintained review already exists. Finally, every effort was made to consider as to whether there were possibilities for missing comparisons that no one had ever investigated.

\section{Results}

There has been considerable research activity involving the three 'essential' antipsychotics (Table 1) and also comparing those three drugs to others on the 'essential' list (Table 2). We found a total of 490 studies with 77957 participants for haloperidol, 316 studies with 29179 participants for chlorpromazine and 33 studies with 4503 participants for fluphenazine decanoate. Reviewing activity has also been considerable in this area but there are notable omissions 
Table 1 WHO three essential antipsychotics and possible comparisons

\begin{tabular}{|c|c|c|c|c|c|}
\hline & RCTs & Total number of people & Cochrane review & Reference & Up to date? \\
\hline \multicolumn{6}{|l|}{ Chlorpromazine } \\
\hline vs fluphenazine depot & 7 & 1314 & $\checkmark$ & {$[13]$} & $x$ \\
\hline vs haloperidol & 51 & 6001 & $\checkmark$ & [14] & $x$ \\
\hline vs placebo & 233 & 19854 & $\checkmark$ & {$[15]$} & $x$ \\
\hline Withdrawal & 1 & 32 & $\checkmark$ & {$[16]$} & $x$ \\
\hline Techniques of administration & 8 & 669 & $x$ & & \\
\hline Dose & 15 & 1279 & $\checkmark$ & {$[17]$} & $x$ \\
\hline In specific circumstances & 1 & 30 & $\checkmark$ & {$[18]$} & $x$ \\
\hline \multicolumn{6}{|l|}{ Fluphenazine Decanoate } \\
\hline vs chlorpromazine & 7 & 1314 & $\checkmark$ & {$[13]$} & $x$ \\
\hline vs haloperidol & 19 & 2339 & $\checkmark$ & [13] & $x$ \\
\hline vs placebo & 4 & 456 & $\checkmark$ & [13] & $x$ \\
\hline Withdrawal & 0 & 0 & $x$ & & \\
\hline Techniques of administration & 0 & 0 & $x$ & & \\
\hline Dose & 3 & 394 & $x$ & & \\
\hline In specific circumstances & 0 & 0 & $x$ & & \\
\hline \multicolumn{6}{|l|}{ Haloperidol } \\
\hline vs chlorpromazine & 51 & 6001 & $\checkmark$ & {$[14]$} & $x$ \\
\hline vs fluphenazine depot & 19 & 2339 & $\checkmark$ & [13] & $x$ \\
\hline vs placebo & 237 & 41321 & $\checkmark$ & [19] & $x$ \\
\hline Withdrawal & 3 & 126 & $x$ & & \\
\hline Techniques of administration & 50 & 10583 & $x$ & & \\
\hline Dose & 126 & 16470 & $\checkmark$ & {$[20]$} & $x$ \\
\hline In specific circumstances & 4 & 1117 & $\checkmark$ & {$[21]$} & $x$ \\
\hline
\end{tabular}

RCTs: Randomized Controlled Trials

Vs: Versus

$\checkmark$ : Systematic Reviews or updates already exist

$x$ : Systematic Reviews or updates do not exist

which would necessitate new reviews to comprehensively cover the area.

\section{Discussion}

We have used the 'sample frame' of the WHO Essential drug list as a starting point. WHO prioritises for us those drugs that have universal accessibility but they may not be the compounds that are first choice if others are available. Also, we have not considered comparisons of drugs with other interventions such as psychotherapies, techniques of management, and other physical treatment such as electro-convulsant therapy. Studies relevant to these comparisons do exist and recognise that the scope of our list of comparisons is limited. However, these other treatments are not listed by WHO as essential (except for treatment of every person with respect and dignity), they are not known to be universally accessible, and they are more difficult to define for global purposes of comparison. Confining the list to drugs only makes this list of comparisons serviceable. There may well be, therefore, other comparisons with universally accessible [non-pharmacological] treatments that we have not considered.

The key antipsychotics have been compared with many other drugs that fall into the broad categories seen within Table 2 . We have not attempted to categorise every possible combination as we did for Table 1 . Clearly researchers have undertaken many trials of treatments, even if used in a less than conventional way, using the three essential antipsychotics and compared them with other drugs. Many of these comparisons would seem odd or unusual but in situations where very few alternatives exist some less conventional alternative treatments may be considered. These have been much less commonly considered by reviewers and this exercise has highlighted that some should be the focus of reviews of the future.

It is encouraging to see how many maintained reviews already exist to service those undertaking WHO guidelines. This effort has been because of the foresight of reviewers, editors and sometimes funders (for the larger of the reviews). Most reviews, however, are not fully up- 
Table 2 WHO three essential antipsychotics and other drugs on the 'Essential' list (by drug class) to which they have been compared within randomized trials

\begin{tabular}{|c|c|c|c|c|c|}
\hline & RCTs & Total number of people & Cochrane review & Reference & Up to date? \\
\hline \multicolumn{6}{|l|}{ Chlorpromazine } \\
\hline vs anticonvulsant agents & 2 & 118 & $x$ & & \\
\hline vs antidepressants & 12 & 732 & $\checkmark$ & {$[22,23]$} & $x$ \\
\hline vs antihypertensive agents & 8 & 286 & $x$ & & \\
\hline vs antiparkinsonian agents & 3 & 80 & $x$ & & \\
\hline vs antituberculosis agents & 1 & 25 & $x$ & & \\
\hline vs barbiturates & 3 & 750 & $x$ & & \\
\hline vs benzodiazepines & 9 & 457 & $\checkmark$ & {$[24,25]$} & $x$ \\
\hline vs mood stabilizers & 2 & 49 & $\checkmark$ & {$[26-28]$} & $x$ \\
\hline vs opioid agonist & 1 & 340 & $x$ & & \\
\hline vs opioid antagonist & 1 & 60 & $x$ & & \\
\hline \multicolumn{6}{|l|}{ Fluphenazine decanoate } \\
\hline vs antihypertensive agents & 1 & 17 & $x$ & & \\
\hline vs antituberculosis agents & 1 & 55 & $x$ & & \\
\hline \multicolumn{6}{|l|}{ Haloperidol } \\
\hline vs antiarrhythmic agents & 2 & 30 & $x$ & & \\
\hline vs antidepressants & 10 & 774 & $\checkmark$ & {$[22,23]$} & $x$ \\
\hline vs antidopaminergic agents & 4 & 146 & $x$ & & \\
\hline vs antigout agents & 1 & 46 & $x$ & & \\
\hline vs antihypertensive agents & 3 & 122 & $x$ & & \\
\hline vs antineoplastic agents & 3 & 101 & $x$ & & \\
\hline vs antiparkinsonian agents & 8 & 265 & $x$ & & \\
\hline vs antiprogesterone agents & 1 & 80 & $\checkmark$ & {$[29]$} & $x$ \\
\hline vs benzodiazepines & 35 & 4012 & $\checkmark$ & {$[24,25]$} & $x$ \\
\hline vs ethanol & 1 & 35 & $x$ & & \\
\hline vs glucose & 1 & unclear & $x$ & & \\
\hline vs mood stabilizers & 23 & 1648 & $\checkmark$ & {$[26-28]$} & $x$ \\
\hline vs stimulant agents & 1 & 20 & $x$ & & \\
\hline
\end{tabular}

RCTs: Randomized Controlled Trials

Vs: Versus

$\checkmark$ : Systematic Reviews or update already exist

$x$ : Systematic Reviews or update do not exist

to-date. Even with reviews of older drugs and, therefore, less active areas of research, there remains the challenge of update. We expect that new fresh reviews meeting the needs of WHO and updates of not fully up-to-date reviews will be used to regularly update the WHO list of essential medicines and other lists of medicines included in formularies or emergency kits [12].

New techniques are being introduced to the science of data synthesis that allow use of more of the older data or at the very least their reconsideration. These include more explicit and transparent evaluation of potential risk of bias in the design of included studies, the possibility to explore the diversity of the results of different studies included in the analysis (heterogeneity), and the possibility to summarize the results of systematic reviews and meta-analyses into "Summary of Findings (SoF) tables".

\section{Conclusions}

The needs of those guiding care can be taken as a means of prioritising research. For largest global impact WHO Essential Medicine list provides clear direction. By using this technique workload can be anticipated, prioritising can take place for new reviews and updates.

\section{Author details}

'Department of Public Health and Community Medicine, Section of Psychiatry and Clinical Psychology, University of Verona, Verona, Italy. ${ }^{2}$ Division of Psychiatry, University of Nottingham, Nottingham, UK.

\section{Authors' contributions}

MP, CEA and CB designed the study. MP extracted data, CEA analysed and interpreted data. MP and CEA drafted the first manuscript. CB commented and refined the manuscript in preparation for submission. All authors approved the final version to be published.

\section{Competing interests}

The authors declare that they have no competing interests. 
Received: 6 June 2011 Accepted: 24 September 2011

Published: 24 September 2011

\section{References}

1. The Cochrane Collaboration: Working together to provide the best evidence for health care [Internet]., [cited 2011 May 16];Available from: http://www.cochrane.org/.

2. Jadad AR, Cook DJ, Jones A, Klassen TP, Tugwell P, Moher M, Moher D: Methodology and reports of systematic reviews and meta-analyses: a comparison of Cochrane reviews with articles published in paper-based journals. JAMA 1998, 280:278-280.

3. Doyle J, Waters E, Yach D, McQueen D, De Francisco A, Stewart T, Reddy P, Gulmezoglu AM, Galea G, Portela A: Global priority setting for Cochrane systematic reviews of health promotion and public health research. J Epidemiol Community Health 2005, 59:193-197.

4. WHO: Evaluation of methods for the treatment of mental disorders. Report of a WHO Scientific Group on the Treatment of Psychiatric Disorders. World Health Organ Tech Rep Ser 1991, 812:1-75.

5. WHO: mhGAP Intervention Guide for mental, neurological and substance use disorders in non-specialized health settings [Internet]., [cited 2011 Jan 6];Available from: http://www.who.int/mental_health/evidence/ mhGAP_intervention_guide/en/index.html.

6. WHO: Essential medicines [Internet]., [cited 2011 May 17];Available from: http://www.who.int/topics/essential_medicines/en/.

7. WHO: WHO List of rejected drugs from the list of Essential Medicines [Internet]., [cited 2011 May 25];Available from: http://www.who.int/ selection_medicines/committees/REJECTIONS.pdf.

8. Guyatt G, Oxman AD, Akl E, Kunz R, Vist G, Brozek J, Norris S, Falck-Ytter Y, Glasziou P, DeBeer H, Jaeschke R, Rind D, Meerpohl J, Dahm P, Schünemann HJ: GRADE guidelines 1. Introduction-GRADE evidence profiles and summary of findings tables. J Clin Epidemiol 2011, 64:383-94

9. Barbui C, Dua T, van Ommeren M, Yasamy MT, Fleischmann A, Clark N, Thornicroft G, Hill S, Saxena S: Challenges in Developing Evidence-Based Recommendations Using the GRADE Approach: The Case of Mental, Neurological, and Substance Use Disorders. PLoS Med 2010, 7:e1000322.

10. Cochrane Schizophrenia Group Specialised Register: Cochrane Schizophrenia Group [Internet]., [cited 2011 May 17];Available from: http://szg.cochrane.org/cochrane-schizophrenia-group-specialised-register.

11. Thornley B, Adams C: Content and quality of 2000 controlled trials in schizophrenia over 50 years. BMJ 1998, 317:1181-1184.

12. van Ommeren M, Barbui C, de Jong K, Dua T, Jones L, Perez-Sales $P$, Schilperoord M, Ventevogel P, Yasamy MT, Saxena S: If You Could Only Choose Five Psychotropic Medicines: Updating the Interagency Emergency Health Kit. PLoS Med 2011, 8:e1001030.

13. David A, Adams CE, Eisenbruch M, Quraishi S, Rathbone J: Depot fluphenazine decanoate and enanthate for schizophrenia. Cochrane Database Syst Rev 2005, 1:CD000307.

14. Leucht C, Kitzmantel M, Chua L, Kane J, Leucht S: Haloperidol versus chlorpromazine for schizophrenia. Cochrane Database Syst Rev 2008, 1 : CD004278.

15. Adams CE, Awad G, Rathbone J, Thornley B: Chlorpromazine versus placebo for schizophrenia. Cochrane Database Syst Rev 2007, 2:CD000284.

16. Almerie MQ, Alkhateeb H, Essali A, Matar HE, Rezk E: Cessation of medication for people with schizophrenia already stable on chlorpromazine. Cochrane Database Syst Rev 2007, 1:CD006329.

17. Liu X, De Haan S: Chlorpromazine dose for people with schizophrenia. Cochrane Database Syst Rev 2009, 2:CD007778.

18. Ahmed U, Jones H, Adams CE: Chlorpromazine for psychosis induced aggression or agitation. Cochrane Database Syst Rev 2010, 4:CD007445.

19. Joy CB, Adams CE, Lawrie SM: Haloperidol versus placebo for schizophrenia. Cochrane Database Syst Rev 2006, 4:CD003082

20. Waraich PS, Adams CE, Roque M, Hamill KM, Marti J: Haloperidol dose for the acute phase of schizophrenia. Cochrane Database Syst Rev 2002, 3: CD001951.

21. Huf G, Alexander J, Allen MH, Raveendran NS: Haloperidol plus promethazine for psychosis-induced aggression. Cochrane Database Syst Rev 2009, 3:CD005146.

22. Rummel C, Kissling W, Leucht S: Antidepressants for the negative symptoms of schizophrenia. Cochrane Database Syst Rev 2006, 3 : CD005581.
23. Whitehead C, Moss S, Cardno A, Lewis G: Antidepressants for people with both schizophrenia and depression. Cochrane Database Syst Rev 2002, 2: CD002305.

24. Volz A, Khorsand V, Gillies D, Leucht S: Benzodiazepines for schizophrenia. Cochrane Database Syst Rev 2007, 1:CD006391.

25. Gibson RC, Walcott G: Benzodiazepines for catatonia in people with schizophrenia and other serious mental illnesses. Cochrane Database Syst Rev 2008, 4:CD006570.

26. Leucht S, Kissling W, McGrath J: Lithium for schizophrenia. Cochrane Database Syst Rev 2007, 3:CD003834.

27. Basan A, Leucht S: Valproate for schizophrenia. Cochrane Database Syst Rev 2004, 1:CD004028.

28. Leucht S, Kissling W, McGrath J, White P: Carbamazepine for schizophrenia. Cochrane Database Syst Rev 2007, 3:CD001258

29. Chua WL, de Izquierdo SA, Kulkarni J, Mortimer A: Estrogen for schizophrenia. Cochrane Database Syst Rev 2005, 4:CD004719.1.

doi:10.1186/1752-4458-5-25

Cite this article as: Purgato et al.: Using the needs of WHO to prioritise Cochrane reviews: The case of antipsychotic drugs. International Journal of Mental Health Systems 2011 5:25.

\section{Submit your next manuscript to BioMed Central and take full advantage of:}

- Convenient online submission

- Thorough peer review

- No space constraints or color figure charges

- Immediate publication on acceptance

- Inclusion in PubMed, CAS, Scopus and Google Scholar

- Research which is freely available for redistribution

Submit your manuscript at www.biomedcentral.com/submit
C Biomed Central 